\title{
Esto no lo estudié en la carrera
}

\author{
Gemma BARRERA GIL \\ Escola Montserrat, Rubí \\ gemma.barrera@escolamontserrat.cat
}

Despedirte de tus alumnos un jueves y no volverlos a ver hasta meses después... ¿Quién nos iba a decir, en febrero de 2020, que algo así ocurriría? Definitivamente, nadie podía esperar lo que iba a suceder, y no estábamos preparados para ello.

Días de improvisar, probar métodos nuevos, adaptarnos a una realidad con la que no habíamos convivido... Clases online (en estos momentos están a la orden del día, pero en marzo de 2020 pocos estábamos familiarizados con el Classroom, el Meet, formularios o Drives), digitalizar material y preparar pruebas a distancia. Los apuntes en la pizarra se convirtieron en presentaciones que teníamos que preparar con prisas; las clases a viva voz, en un intento por mantener a los estudiantes atentos y conectados con los demás; las confidencias del recreo quedaron en breves correos electrónicos faltos de esa complicidad y calidez de nuestra cercanía... La preocupación por saber cómo enseñarles tal o cual materia, pero también por cómo toda la situación podía afectarles a nivel emocional (hoy sabemos que mucho).

Finalizaba en junio un curso en el que muchos se habían perdido su última fiesta de graduación, su viaje de fin de curso o, simplemente, el abrazo de su compañero, amigo o tutor del año... Pensábamos que en verano todo estaría más tranquilo, aunque los Equipos Directivos trabajaban sin descanso por lograr un Plan de Apertura de Centros adecuado a la situación de la pandemia. Pandemia. Qué palabra tan utilizada en estos momentos y qué poco sabíamos de ella hace un tiempo. Parecía lejana, casi imposible... Hoy sabemos que esta pandemia llegó hace casi dos años para quedarse.

En septiembre abrimos los centros con mucha ilusión, pero también con mucho miedo. El Plan de Apertura de Centro de junio nada tenía que ver con el de septiembre, que de igual modo fue variando a lo largo de las primeras semanas de curso...

Mascarilla, hidrogel, control de temperatura, entradas escalonadas para evitar aglomeraciones, grupos burbuja... iNo toques la barandilla! iTose al codo! iNo compartas el lápiz! iNo te acerques tanto!... ¿Dónde ha quedado la cercanía, el acompañamiento, el consuelo? De momento, queda aparcado, aunque intentamos buscar las vías de compensar esas carencias. Y sonreímos con los ojos, abrazamos en la distancia y cuidamos desde la empatía.

En este primer curso posconfinamiento todos éramos noveles, todos teníamos que aprender cosas y amoldarnos a la nueva situación. Seguía el miedo, el respeto... Si oíamos una tos, nos asustábamos; si les dolía la cabeza, corríamos a por el termómetro. Se acabaron las charlas en la sala de profesores y los cafés y aparecieron las miradas cómplices, los "cómo vas" y los "te entiendo" entre líneas. 
Poco a poco fuimos adaptándonos a esta forma de hacer y, cada vez que había un grupo confinado, las clases salían con más naturalidad y soltura. Si algo bueno tiene esta época que estamos viviendo es que aflora la creatividad, de eso no hay duda.

Y, a trompicones y con mucho esfuerzo, acabó el primer curso de mascarillas, gel y distancia que tanto costó.

Comenzar de nuevo en septiembre ya no asustaba tanto. Habíamos practicado durante un año entero. Los alumnos también. Ya con el hábito del gel, ya con la experiencia de un año atípico, pero que habían logrado superar, y con nota. Campeones. Sois unos campeones.

Indudablemente, hemos aprendido que el poder de adaptación de los niños y los jóvenes es infinito, aun sabiendo que son los que más necesitan el contacto, las relaciones sociales y las muestras de cariño. Hemos aprendido a reinventarnos, a buscar fórmulas para conseguir lo que queremos. En definitiva, a hacer de esta excepcionalidad nuestra nueva realidad. Y aunque parecía que los días de pandemia tocaban a su fin, aquí estamos de nuevo, sumando contagios, contando camas de hospital y volviendo a sentir ese miedo y ese respeto del 2020. 